\title{
Lutetium-177-PSMA therapy for prostate cancer patients - a brief overview of the literature
}

\author{
Ludwike W. M. van Kalmthout · Esmée C. A. van der Sar - Arthur J. A. T. Braat - Bart de Keizer · \\ Marnix G. E. H. Lam
}

Published online: 26 August 2020

(C) The Author(s) 2020

\begin{abstract}
Radioligand therapy with lutetium-177 prostate specific membrane antigen ([177 Lu]Lu-PSMA) represents a promising treatment for metastatic castration-resistant prostate cancer patients. In this paper, we aim to summarize the current knowledge derived from the literature as well as the authors' experiences on $\left[{ }^{177} \mathrm{Lu}\right] \mathrm{Lu}-\mathrm{PSMA}$ therapy. Various systematic reviews, mostly including small retrospective studies, summarized efficacy and oncological outcomes of $\left[{ }^{177} \mathrm{Lu}\right] \mathrm{Lu}-\mathrm{PSMA}$ therapy. Any therapyrelated prostate-specific antigen (PSA) response was reported in the majority of the patients $(68-75 \%)$; $>50 \%$ PSA decline was demonstrated in $34.5-51 \%$ of the patients. Incidence of side effects was low and in most patients, hematological toxicity remained limited to Common Terminology Criteria for Adverse Events (CTCAE) grade 1-2. Also, favorable efficacy was shown with regard to tumor response on imaging, pain symptoms and quality of life. In the near future, results of the awaited pivotal prospective studies (NCT03511664, NCT03392428) will define efficacy of $\left.{ }^{[177} \mathrm{Lu}\right] \mathrm{Lu}-\mathrm{PSMA}$ therapy and its oncological value for metastatic castration-resistant prostate cancer patients.
\end{abstract}

Keywords $\left.{ }^{177} \mathrm{Lu}\right] \mathrm{Lu}-\mathrm{PSMA} \cdot$ Radioligand therapy · Castration-resistant prostate cancer

\section{Lutetium-177 PSMA therapie voor patiënten met prostaatkanker - een kort overzicht van de literatuur}

Samenvatting Radioligand therapie met lutetium177 prostaat specifiek membraan antigeen $\left(\left[{ }^{177} \mathrm{Lu}\right] \mathrm{Lu}-\right.$ PSMA) lijkt een veelbelovende behandeling voor gemetastaseerde, castratieresistente prostaatkankerpatiënten. In dit overzichtsartikel wordt de bestaande kennis uit de literatuur met betrekking tot $\left[{ }^{177} \mathrm{Lu}\right] \mathrm{Lu}-$ PSMA therapie, alsmede de ervaringen van de auteurs samengevat. Effectiviteit en oncologische uitkomsten van $\left[{ }^{177} \mathrm{Lu}\right] \mathrm{Lu}-\mathrm{PSMA}-\mathrm{therapie}$ werden samengevat door verschillende systematische reviews, die hoofdzakelijk kleine retrospectieve studies includeerden. Bij meer dan de helft van de patiënten (68-75\%) werd een PSA-respons na therapie gevonden. Een prostaatspecifiek antigeen (PSA)-daling van $>50 \%$ werd geobserveerd bij 34,5-51\% van de patiënten. De meest voorkomende bijwerkingen (o.a. xerostomie) en hematologische toxiciteit bleven grotendeels beperkt tot Common Terminology Criteria for Adverse Events (CTCAE) graad 1-2. Ook werd een gunstig effect beschreven op beeldvorming, pijnklachten en kwaliteit van leven. In de nabije toekomst zal meer bekend worden over de definitieve waarde van $\left[{ }^{177} \mathrm{Lu}\right] \mathrm{Lu}-\mathrm{PSMA}$ radioligandtherapie voor gemetastaseerde, castratieresistente prostaatkankerpatiënten door de resultaten van groot opgezette prospectieve studies (NCT03511664, NCT03392428).

Trefwoorden $\left[{ }^{177} \mathrm{Lu}\right]-\mathrm{PSMA} \cdot$ radioligand therapie castratieresistente prostaatkanker

\section{Introduction}

With 13,557 deaths in 2019, prostate cancer (PCa) is an important cause of cancer mortality in the Nether-
L. W. M. van Kalmthout, MD ( $\varangle)$. drs. E. C. A. van der Sar, MD · A. J. A. T. Braat, $\mathrm{PhD} \cdot$ B. de Keizer, PhD . Dept. of Radiology and Nuclear Medicine, University Medical Center Utrecht, Utrecht, The Netherlands L.W.M.vanKalmthout-2@umcutrecht.nl 
lands, driven by PCa patients who no longer respond to hormonal therapy [1]. A proportion of $10-20 \%$ of the PCa patients will eventually progress to metastatic castration-resistant prostate cancer (mCRPC) [2]. Since PCa metastases have a preference for bone (marrow), approximately $90 \%$ of these patients develop bone metastases. Common clinical presentations include pain, fatigue, bone marrow depression or complications such as fractures and cord compression [3]. Standard treatment options in advanced PCa patients include chemotherapy (docetaxel and cabazitaxel) and new hormonal agents (enzalutamide and abiraterone). However, these therapies are associated with substantial side effects. Also, for some patients, chemotherapy is not tolerated well or even contraindicated. Therefore, novel therapeutic strategies for mCRPC patients with improved outcomes and minimal side effects are profoundly needed.

The past years, Prostate-Specific Membrane Antigen (PSMA) targeting radioligand therapy became focus of attention. PSMA is a type II transmembrane glycoprotein, also known as folate hydrolase or glutamate carboxypeptidase II. It is highly overexpressed by the cell surface of $90-100 \%$ of all prostate cancers, and has 100-1000 fold lower expression on normal prostate cells. Physiological PSMA expression is found on the duodenal mucosa, proximal renal tubules, and salivary glands [4-6]. Additionally, PSMA overexpression on tumor cells is associated with high-grade, de-differentiated, metastatic, castration-resistant PCa [7]. The differential expression of PSMA from tumor to non-tumor tissue has evolved in several targeted strategies including tumor localization using radioactive imaging (with Gallium-68 $\left.\left({ }^{68} \mathrm{Ga}\right]\right)$ and Fluor-18 $\left.\left(\left[{ }^{18} \mathrm{~F}\right]\right)\right)$ and therapeutic intervention using radioli-
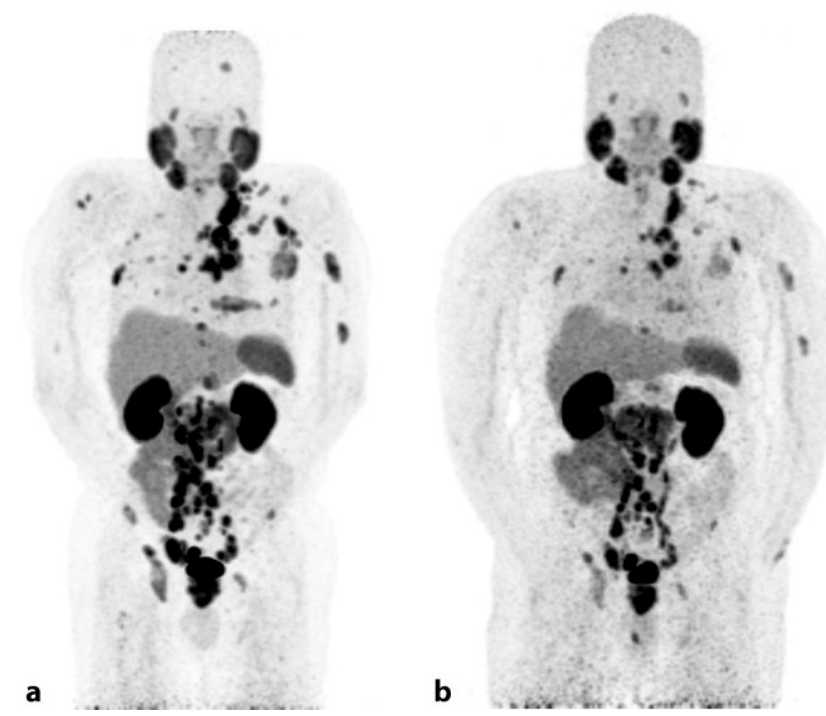

Fig. 1 Baseline (a) and follow-up (b after 2 cycles; c after 4 cycles; $\mathbf{d}$ after 6 cycles) $\left[{ }^{68} \mathrm{Ga}\right] \mathrm{Ga}$-PSMA PET/CT of a patient with mCRPC, who was treated with $6.0 \mathrm{GBq}\left[{ }^{177} \mathrm{Lu}\right] \mathrm{Lu}-$ PSMA-617 (Novartis, Basel, Switserland). Prostate-specific gand therapy (RLT; with Lutetium-177 ([177 Lu]) and Actinium-223 ([223Ac] )), see Fig. 1.

\section{PSMA ligands}

For many years, RLT was exclusively reserved for palliation of bone metastases. Common treatments for metastatic PCa patients include $\left[{ }^{153} \mathrm{Sm}\right] \mathrm{Sm}$-labeled ethylene diamine tetramethylene phosphonate ([ $\left.{ }^{153} \mathrm{Sm}\right] \mathrm{Sm}$-EDTMP; Quadramet, Lantheus, North Billerica, Massachusetts, United States) and the calcium mimetic alfa emitter [223Ra]Ra-labeled dichloride (Xofigo, Bayer Healthcare, Leverkusen, Nordrhein Westfalen, Germany), of which the latter demonstrated an improved overall survival of 3.6 months [8]. The first studied PSMA targeting compound was termed [ $\left.{ }^{111} \mathrm{In}\right]$ In-capromab pendetide (Prostascint, Cytogen Corp., Princeton, New Jersey, United States). This antibody developed for radioimmunoscintigraphy in PCa patients targeted the intracellular part of the PSMA receptor. Subsequently, to improve uptake and sensitivity, the potential of the $\left[{ }^{177} \mathrm{Lu}\right] \mathrm{Lu}-$ labelled PSMA monoclonal antibody J-591, was investigated [9]. In a phase I and phase II study, this compound was found to have modest effect and was found to be associated with serious myelosuppression, as were all other aforementioned bonetargeting radioligand therapies [10-12]. The perspective on RLT changed with the development of the novel small-molecule PSMA targeting radioligands (or 'radiotracers') [ $\left.{ }^{177} \mathrm{Lu}\right] \mathrm{Lu}-\mathrm{PSMA}-617$ and $\left[{ }^{177} \mathrm{Lu}\right] \mathrm{Lu}-$ PSMA-I\&T, being composed of the PSMA receptor targeting ligand PSMA, labeled with the radioisotope and $\beta$-radiation emitter $\left[{ }^{177} \mathrm{Lu}\right] \mathrm{Lu}$ and a binding agent ('chelator'). When the radioligand $\left[{ }^{177} \mathrm{Lu}\right] \mathrm{Lu}-\mathrm{PSMA}$

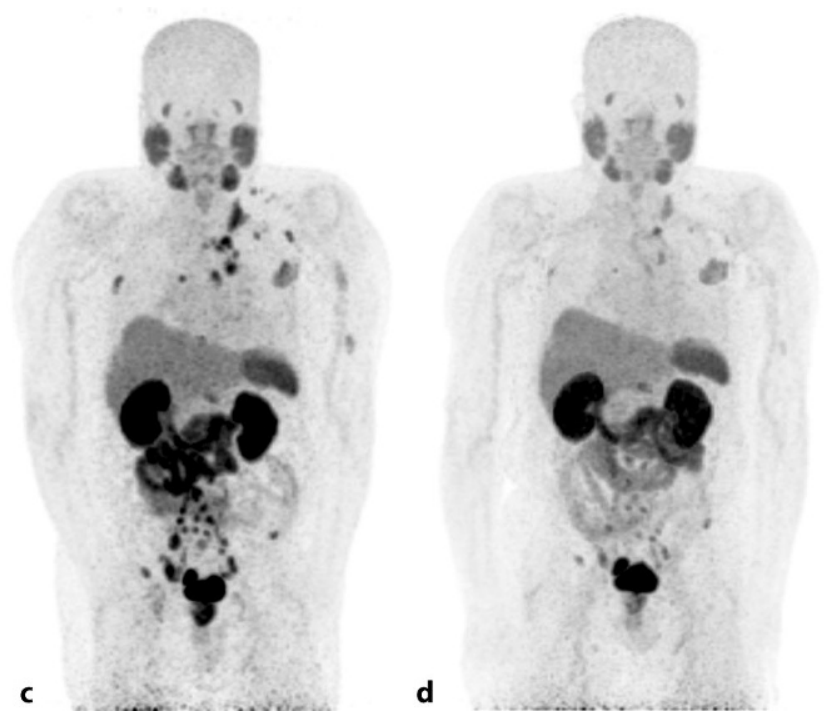

antigen (PSA) response was as follows: $100 \mathrm{ng} / \mathrm{ml}$ (baseline), $190 \mathrm{ng} / \mathrm{ml}$ (after 2 cycles), $52 \mathrm{ng} / \mathrm{ml}$ (after 4 cycles) and $19 \mathrm{ng} / \mathrm{ml}$ (after 6 cycles) 
binds with high affinity to the extracellular domain of the PSMA receptor, the radiotracer is transported into the cell through endocytosis, resulting in local radiation of PCa cells, intracellular DNA damage and apoptosis.

In 2015, development of $\left.{ }^{[177} \mathrm{Lu}\right] \mathrm{Lu}-\mathrm{PSMA}-617$ for the treatment of patients with metastatic prostate cancer was initiated by the German Cancer Research Center 'Deutsches Krebsforschungszentrum' (DKFZ) in collaboration with the University Hospital Heidelberg $[13,14]$. Based on preclinical data demonstrating favorable characteristics (high PSMA binding affinity and compound internalization, prolonged tumor uptake, rapid kidney clearance, and high tumor-to-background ratio), $\left.{ }^{177} \mathrm{Lu}\right] \mathrm{Lu}-\mathrm{PSMA}$ was clinically developed at investigative sites in Germany. Also, in an attempt to further optimize affinity of the PSMA tracer, another PSMA targeting ligand, termed PSMA-Imaging and Therapy (I\&T), was developed in München [15]. Despite the fact that the molecular structures of $\left[{ }^{177} \mathrm{Lu}\right] \mathrm{Lu}-\mathrm{PSMA}-617$ and $\left[{ }^{177} \mathrm{Lu}\right] \mathrm{Lu}-$ PSMA-I\&T are built out of different chelator agents (respectively DOTA and DOTAGA), the two tracers were found to have comparable biodistribution [16]. Several retrospective, single-arm studies were initiated and demonstrated safety, promising efficacy and limited toxicity of radioligand therapy with $\left[{ }^{177} \mathrm{Lu}\right] \mathrm{Lu}-$ PSMA-617 and $\left[{ }^{177} \mathrm{Lu}\right] \mathrm{Lu}-\mathrm{PSMA}-\mathrm{I} \& \mathrm{~T}$ in patients with mCRPC [17-24]. These results induced the provision of $\left.{ }^{177} \mathrm{Lu}\right] \mathrm{Lu}$-PSMA- 617 on the basis of 'compassionate use' at several institutions in Europa, even while the outcomes of randomized-controlled trials and-presumably—subsequent approval for clinical use are still awaited.

\section{Indications}

The decision whether or not an individual patient is eligible for treatment with $\left.{ }^{[177} \mathrm{Lu}\right] \mathrm{Lu}$-PSMA RLT is dependent on clinical assessment and evaluation of imaging and laboratory findings and is made by a multidisciplinary tumor board. In general, mCRPC patients who 1) have failed or are ineligible for alternative cytotoxic treatment options and 2) have adequate organ function and 3) show adequate radiotracer uptake on PSMA PET/CT prior to therapy are

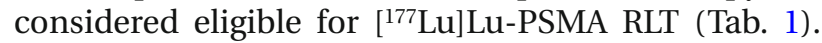
However, the definition of 'adequate uptake' is a topic for discussion. Current practice is based on previous literature on neuroendocrine theranostics, in which uptake in tumor sites must at least be higher than physiological uptake in normal organs, such as the liver.

\section{Treatment protocol}

To date, the optimal administered activity of $\left[{ }^{177} \mathrm{Lu}\right] \mathrm{Lu}$ PSMA RLT per cycle has still not been clarified. The currently administered activity $\left.{ }^{[177} \mathrm{Lu}\right] \mathrm{Lu}$-PSMA-617
Table 1 Current indications for $\left[{ }^{177}\right.$ Lu] Lu-PSMA-617 therapy

Life expectancy $>6$ months (Eastern Cooperative Oncology Group (ECOG) performance status $0-2$ )

Histological, pathological, and/or cytological confirmation of $\mathrm{PCa}$

Prior orchiectomy and/or ongoing androgen-deprivation therapy and a castrate level of serum testosterone $(<50 \mathrm{ng} / \mathrm{dL}$ or $<1.7 \mathrm{nmol} / \mathrm{L})$

$\geq 1$ previous NAAD (enzalutamide and/or abiraterone) and 1-2 previous taxane regimens, or incapability to undergo taxane regimens

No previous RLT or hemi-body irradiation within 6 months prior to treatment commencement

Progressive mCRPC (serum PSA progression, soft-tissue progression or progression of bone disease)

Adequate organ function:

- Serum creatinine $<150 \mu \mathrm{mol} / \mathrm{L}$ or eGFR $>30 \mathrm{ml} / \mathrm{min} . / 1.73 \mathrm{~m}^{2}$

- Liver enzymes $<5$ fold ULN

- Hemoglobin $\geq 5.5 \mathrm{mmol} / \mathrm{L}$

- White blood cell count $\geq 3 \times 10^{9} / \mathrm{L}$

- Absolute neutrophil count $>1.5 \times 10^{9} / \mathrm{L}$

- Platelet count $\geq 100 \times 10^{9} / \mathrm{L}$

Positive PSMA PET/CT (visual assessment; radiotracer uptake in tumor sites preferably significantly greater than uptake in normal liver parenchyma) No baseline superscan (skeletal scintigraphy)

No symptomatic spinal cord compression, or clinical or radiologic findings indicative of impending cord compression

eGFR estimated Glomerular Filtration Rate, ECOG Eastern Cooperative Oncology Group, NAAD Novel Androgen Axis Drug, ULN Upper Limit of Normal

ranges from $6.0-7.5 \mathrm{GBq}$ per cycle, in 2-6 cycles, with an interval of 6-8 weeks. This variety is a result of the evidence generated by previous observational cohort studies, in which patients received a median radiotracer activity of $6.0 \mathrm{GBq}$ (range: $3.7-9.3 \mathrm{GBq}$ ), and the recently published phase II study, in which a fixed activity of $7.5 \mathrm{GBq}$ was administered [25]. At present, only one dose-escalation study was performed so far, which reports on 40 patients who underwent treatment with $4.0 \mathrm{GBq}, 6.0 \mathrm{GBq}, 7.4 \mathrm{GBq}$ or $9.3 \mathrm{GBq}$ $\left[{ }^{177} \mathrm{Lu}\right] \mathrm{Lu}-\mathrm{PSMA}-617$ [26]. Despite the fact that occurrence of $\geq$ grade 3 toxicities was limited and equally divided among the treatment activity groups, a large proportion of patients treated with $9.3 \mathrm{GBq}$ did not complete the three planned cycles as a result of incomplete recovery of haematological toxicities. This may suggest that the maximum tolerated dose in this group was reached. Future comparative studies are required to define the optimal dosage.

To receive $\left[{ }^{177} \mathrm{Lu}\right] \mathrm{Lu}-\mathrm{PSMA}-617$ therapy, patients are admitted to the nuclear medicine ward for treatment and released from the hospital according to Dutch regulatory radiation guidelines $(20 \mathrm{uSv} / \mathrm{h}$ measured at a distance of $1 \mathrm{~m})$. $\left.\quad{ }^{177} \mathrm{Lu}\right] \mathrm{Lu}$-PSMA-617 is administered by slow infusion $(20 \mathrm{ml} / \mathrm{min}$ flow rate). To prevent nausea, antiemetic drugs are supplied. To monitor biochemical response and toxicity, laboratory tests (full blood count, kidney and liver function tests and PSA) are executed after every treatment cycle. Posttherapeutic scintigraphy following every therapy cycle is performed to investigate radiotracer uptake, which may serve to evaluate imaging response of PSMA pos- 
itive lesions. After two, four and six cycles, $\left[{ }^{68} \mathrm{Ga}\right] \mathrm{Ga}-$ PSMA PET/CT scans are performed. Whether or not to continue therapy is discussed in a multidisciplinary tumor board meeting after every two cycles.

\section{Safety and efficacy}

Past years, four systematic reviews/meta-analyses on $\left[{ }^{177} \mathrm{Lu}\right] \mathrm{Lu}-\mathrm{PSMA} \mathrm{RLT}$ were published, in which mainly small, predominantly German studies were included [27-30]. All reviews reported on (one of the following) oncological outcomes including safety and tumor response, clinical parameters and survival effects. Significant variability between the published reviews exists, which is explained by the different publications selected. For example, Calopedos et al. and Von Eyben et al. also included publications reporting on $\left.{ }^{[177} \mathrm{Lu}\right] \mathrm{Lu}-\mathrm{J} 591$ therapy, known to be associated with higher toxicity rates compared to $\left[{ }^{177} \mathrm{Lu}\right] \mathrm{Lu}-$ PSMA-617 and [ $\left.{ }^{177} \mathrm{Lu}\right] \mathrm{Lu}-\mathrm{PSMA}-\mathrm{I} \& \mathrm{~T}$. Moreover, heterogeneity existed with regard to outcomes and followup schemes. Thus, we will only discuss the review of Yadav et al., that focused on small molecule treatments with [ $\left.{ }^{177} \mathrm{Lu}\right] \mathrm{Lu}-\mathrm{PSMA}-617$ and $\left[{ }^{177} \mathrm{Lu}\right] \mathrm{Lu}-\mathrm{PSMA}-$ I\&T only.

The review by Yadav et al. included 16 publications [30]. Thirteen studies reported on $\left.{ }^{[177} \mathrm{Lu}\right] \mathrm{Lu}-$ PSMA-617; two on $\left[{ }^{177} \mathrm{Lu}\right] \mathrm{Lu}-\mathrm{PSMA}-\mathrm{I} \& \mathrm{~T}$ and one on both compounds. Overall pooled proportions of patients who had any PSA-decline and $>50 \%$ PSA decline were respectively $75 \%$ (95\% CI: $70-79 \%)$ and $46 \%$ (40-53\%). Objective tumor response according to the RECIST criteria was reported by eight studies $(n=175$ patients). A proportion of $37.2 \%$ of patients had partial remission, $38.3 \%$ stable disease and $24.5 \%$ progressive disease. Molecular response on PET imaging (according to PERCIST criteria) was reported by eight of the 17 studies ( $n=167$ patients). 74 patients $(44.3 \%)$ had a partial molecular response, 39 patients $(23.4 \%)$ had stable disease, and 54 patients $(32.3 \%)$ had disease progression. Most side effects were mild (Common Terminology Criteria for Adverse Events [CTCAE] grade $1-2$ ) and comprised anemia (23\%), leukopenia $(14.2 \%)$ and thrombocytopenia (15\%). Renal toxicity was reported in $9.5 \%$ of patients. Most important nonhematological toxicity was confined to the salivary glands (i.e. xerostomia; 14.5\%). These results support the safety and efficacy profile of $\left[{ }^{177} \mathrm{Lu}\right] \mathrm{Lu}-\mathrm{PSMA}$ therapy to treat advanced PCa.

In 2018, the first prospective study on $\left[{ }^{177} \mathrm{Lu}\right] \mathrm{Lu}-$ PSMA-617 therapy was published [25]. In this phase II study, including $30 \mathrm{mCRPC}$ patients, 1-4 cycles with 7.5 GBq (range: $4.4-8.7 \mathrm{GBq}$ ) $\left.{ }^{[177} \mathrm{Lu}\right] \mathrm{Lu}-\mathrm{PSMA}-617$ were administered. Main aim of the study was the analysis of PSA response rate and toxicity. Additional primary endpoints included radiological response assessed by CT for soft tissue response only, skeletal scintigraphy, $\left[{ }^{68} \mathrm{Ga}\right] \mathrm{Ga}-\mathrm{PSMA}-\mathrm{PET} / \mathrm{CT}$ and $\left[{ }^{18} \mathrm{~F}\right] \mathrm{F}-\mathrm{FDG}$ PET/CT. Response on $\left[{ }^{68} \mathrm{Ga}\right] \mathrm{Ga}-\mathrm{PSMA} \mathrm{PET} / \mathrm{CT}$ and $\left[{ }^{18} \mathrm{~F}\right] \mathrm{F}-\mathrm{FDG}$
PET/CT was evaluated using Hicks qualitative criteria. In this study, $>50 \%$ PSA decline was observed in $57 \%$ of the patients. Most common toxicities included CTCAE grade 1 xerostomia (87\%), grade 1-2 transient nausea $(50 \%)$ and fatigue $(50 \%)$. Biochemical toxicities included grade 3-4 thrombocytopenia (13\%), grade 3 anemia (13\%) and neutropenia (7\%). In 14 of the 17 patients $(82 \%)$ with measurable disease at baseline, objective imaging response in lymph nodes and visceral lesions was observed. Treatment was even ceased in two patients after two of the four planned cycles, because of an exceptional response to treatment. After two treatment cycles, quality of life according to the European Organization for Research and Treatment of Cancer questionnaire improved with 10 points in $37 \%$ of the patients. PSA progression-free survival was 7.6 months (95\% CI: 6.3-9.0 months). Median overall survival was 13.5 months $(95 \% \mathrm{CI}$ : 10.4-22.7) months. Twenty-two patients (73\%) died during follow-up, most likely as a result of disease progression $(n=21)$. Therapy-related deaths were not reported.

The only Dutch study, addressing efficacy and toxicity of $\left[{ }^{177} \mathrm{Lu}\right] \mathrm{Lu}-\mathrm{PSMA}$ therapy, was published in 2019 [31]. Thirty mCRPC patients underwent $\left[{ }^{177} \mathrm{Lu}\right] \mathrm{Lu}-\mathrm{PSMA}-617$ with a mean activity of $6.0 \mathrm{GBq}$ (5.6-6.4GBq) per cycle. Median number of therapy cycles was four (range: 1-6 cycles) with a planned interval of 6 weeks (range: 5.5-35 weeks). [ $\left.{ }^{68} \mathrm{Ga}\right] \mathrm{Ga}-$ PSMA PET/CT scans were repeated after two, four and six cycles for evaluation of tumor response. A multidisciplinary tumor board discussed whether or not to continue therapy after every two cycles. In case of partial remission or stable disease, further therapy cycles were planned. Treatment was ceased if disease progression was observed. In patients with exceptional response, further treatment cycles were temporarily postponed and restarted after evident biochemical progression. During treatment, PSA-decline of $>50 \%$ and $>90 \%$ was observed in respectively $57 \%$ and $24 \%$ of patients. Despite two patients $(7 \%)$ who suffered from newly originated grade 3-4 anemia, [ $\left.{ }^{177} \mathrm{Lu}\right] \mathrm{Lu}-\mathrm{PSMA}-617$ therapy was generally well tolerated and toxicities were mild (CTCAE grade 1-2). Grade 2 xerostomia was observed in $17 \%$ of the patients. After the first cycle, usage of analgesics decreased in $45 \%$ of patients with pain symptoms at commencement of therapy. In $52 \%$ of patients, these symptoms ameliorated after two cycles. With regard to imaging response on $\left[{ }^{68} \mathrm{Ga}\right] \mathrm{Ga}-\mathrm{PSMA}$ PET/CT $52 \%$, $47 \%$ and $75 \%$ of patients showed a partial response after respectively the second, fourth and sixth cycle, and progressive disease was seen in respectively $17 \%$, $20 \%$ and $0 \%$ of the analyzed patients. Notably, the reported response rates may be influenced by patient selection, since patients suffering from progressive disease were excluded from further treatment cycles. During a median follow-up of 13.7 (range 9.8-32.3) months, median overall survival was 11.3 months 
(range 1.4-32.3 months). 10 patients died during follow-up, mostly due to progressive disease.

\section{Survival}

Little is known about the efficacy of $\left[{ }^{177} \mathrm{Lu}\right] \mathrm{Lu}-\mathrm{PSMA}$ therapy in terms of progression free survival and/or overall survival (OS). Nevertheless, Kim et al. addressed OS based on extent of PSA response (any PSA decline and $>50 \%$ PSA decline) after a single cycle of $\left[{ }^{177} \mathrm{Lu}\right] \mathrm{Lu}-\mathrm{PSMA}$ therapy and found pooled hazard ratios of 0.29 and 0.82 respectively [27]. Von Eyben et al. found a median OS of 14 months in the patients treated with $\left[{ }^{177} \mathrm{Lu}\right] \mathrm{Lu}-\mathrm{PSMA}$ [29]. The median OS of 13.7 months (interquartile range (IQR) 8-14 months), reported by Yadav et al., was congruent with these findings and was found to be superior to the survival of a historical cohort, which had an OS of 11.2 months [30]. Median PFS was found to be 11 months (IQR 7.6-13.7 months). However, to ultimately define value of $\left[{ }^{177} \mathrm{Lu}\right] \mathrm{Lu}-\mathrm{PSMA}-617$ therapy, survival analyses based on prospectively acquired data are warranted.

\section{[177Lu]Lu-PSMA-617 therapy in the Netherlands}

Based on the initially published, promising results, $\left[{ }^{177} \mathrm{Lu}\right] \mathrm{Lu}-\mathrm{PSMA}-617$ therapy was introduced into clinical practice in the University Medical Center Utrecht in the Netherlands in December 2016. Until 2019, $\left[{ }^{177} \mathrm{Lu}\right] \mathrm{Lu}-\mathrm{PSMA}-617$ was administered to advanced mCRPC patients in the clinical setting on a salvage basis, after all other registered treatment strategies had failed. At present, availability of $\left[{ }^{177} \mathrm{Lu}\right] \mathrm{Lu}-\mathrm{PSMA}-$ 617 is confined to the context of scientific research. $\left[{ }^{177} \mathrm{Lu}\right] \mathrm{Lu}-\mathrm{PSMA}-\mathrm{I} \& \mathrm{~T}$ is freely available in the Netherlands, however, this compound is neither registered nor reimbursed.

In 2018, Endocyte/Novartis started a phase 3 trial, known as the VISION-trial (NCT03511664), to prospectively study the efficacy and toxicity profile of $\left[{ }^{177} \mathrm{Lu}\right] \mathrm{Lu}-\mathrm{PSMA}-617$ therapy. Four Dutch hospitals participated in this study, in which 750 metastatic PCa patients were randomly (2:1) assigned to two studyarms: either treatment with $7.4 \mathrm{GBq}\left[{ }^{177} \mathrm{Lu}\right] \mathrm{Lu}-\mathrm{PSMA}-$ 617 per cycle or best supportive care. The results of this study are expected in 2021. In line with the promising initial results of $\left[{ }^{177} \mathrm{Lu}\right] \mathrm{Lu}-\mathrm{PSMA}-617$ therapy, the VISION study is expected to be positive. If indeed so, $\left[{ }^{177} \mathrm{Lu}\right] \mathrm{Lu}-\mathrm{PSMA}-617$ therapy will soon be implemented in daily clinical care in The Netherlands. According to the studied procedures in the VISION study, mCRPC patients will be eligible for treatment once every 6 weeks with a maximum of 6 cycles of 7.4 GBq [ $\left.{ }^{177} \mathrm{Lu}\right] \mathrm{Lu}-\mathrm{PSMA}-617$.

TheraP, another clinical phase 2 trial (NCT03392428) initiated by Endocyte/Novartis, aims to determine the activity and safety of $\left[{ }^{177} \mathrm{Lu}\right] \mathrm{Lu}-\mathrm{PSMA}-617 \mathrm{RLT}$ as a second line treatment and will be performed in Australia.
A total number of 200 patients with metastatic PCa who have progressed despite ADT and chemotherapy, will be randomized to receive either $\left[{ }^{177} \mathrm{Lu}\right] \mathrm{Lu}-\mathrm{PSMA}-$ 617 RLT (up to a maximum of 6 cycles of therapy) or cabazitaxel chemotherapy (up to a maximum of 10 cycles of therapy). The primary endpoint includes the effect of $\left[{ }^{177} \mathrm{Lu}\right] \mathrm{Lu}-\mathrm{PSMA}-617$ on PSA response. Secondary outcomes are pain response, PFS, quality of life, and frequency and severity of adverse events.

\section{Discussion}

For advanced mCRPC patients who failed all standard cytotoxic treatments, $\left[{ }^{177} \mathrm{Lu}\right] \mathrm{Lu}-\mathrm{PSMA}-617$ RLT appears a safe, effective treatment with limited associated side effects. According to the published literature, any PSA response is expected in the vast majority of the patients (68-75\%) and in $35-51 \%$ of the treated patients, $>50 \%$ PSA decline can be expected. In general, [177 Lu]Lu-PSMA-617 therapyassociated hematological toxicity remains limited to CTCAE grade 1-2 (anemia: 23\%, leukopenia: $14.2 \%$ and thrombocytopenia $15 \%$ ). Mild xerostomia, the most frequently reported clinical side effect, can be expected in $8-14.5 \%$ of the patients. Also, favorable efficacy of $\left[{ }^{177} \mathrm{Lu}\right] \mathrm{Lu}-\mathrm{PSMA}-617$ RLT with regard to imaging response and quality of life was reported. In this respect, it must be noted that aforementioned proportions still have to be confirmed by randomizedcontrolled trials.

\section{Future perspectives}

Past years, [ $\left.{ }^{177} \mathrm{Lu}\right] \mathrm{Lu}-\mathrm{PSMA}-617$ RLT was developed to treat patients with advanced PCa in the last phase of their disease. However, it is expected that the indications for [ $\left.{ }^{177} \mathrm{Lu}\right] \mathrm{Lu}-\mathrm{PSMA}-617$ RLT will expand to earlier stages if the VISION trial confirms its efficacy and mild toxicity profile. While the results of prospective clinical trials are awaited, other studies in this field have been initiated (both nationally and internationally) to address relevant research questions.

Open Access This article is distributed under the terms of the Creative Commons Attribution 4.0 International License (http://creativecommons.org/licenses/by/4.0/), which permits unrestricted use, distribution, and reproduction in any medium, provided you give appropriate credit to the original author(s) and the source, provide a link to the Creative Commons license, and indicate if changes were made.

\section{References}

1. IKNL. Cijfers over kanker. 2020. www.cijfersoverkanker.nl. Accessed 27 Mar 2020.

2. Kirby M, Hirst C, CrawfordED. Charaterising the castrationresistant prostate cancer population: a systematic review. Int J Clin Pract. 2011;65(11):1180-92.

3. Hotte SJ, Saad F. Current management of castrate-resistant prostate cancer. Curr Oncol. 2010;17(Suppl2):S72-S9. 
4. Bostwick DG, Pacelli A, Blute M, Roche P, Murphy GP Prostate specific membrane antigen expression in prostatic intraepithelial neoplasia and adenocarcinoma: a study of 184 cases. Cancer. 1998;82:2256-61.

5. Ghosh A, Heston WD. Tumor target prostate specific membrane antigen (PSMA) and its regulation in prostate cancer. JCell Biochem. 2004;91:528-39.

6. Mannweiler S, Amersdorfer P, Trajanoski S, Terrett JA, King D, Mehes G. Heterogeneity of prostate-specific membrane antigen (PSMA) expression in prostate carcinoma with distant metastasis. Pathol Oncol Res. 2009;15(2):167-72.

7. Ross JS, Sheehan CE, Fisher H. Correlation of primary tumor prostate-specific membrane antigen expression with disease recurrence in prostate cancer. Clin Cancer Res. 2003:9:6357-62.

8. ALSYMPCA Investigators, Parker C, Nilsson S, Heinrich D, et al. Alpha emitter radium-223 and survival in metastatic prostate cancer. NEngl J Med. 2013;369:213-23.

9. Liu H, Moy P, Kim S, et al. Monoclonal antibodies to the extracellular domain of prostate-specific membrane antigen also react with tumor vascular endothelium. Cancer Res. 1997;57:3629-34.

10. Gallicchio R, Giacomobono S, Nardelli A, et al. Palliative treatment of bone metastases with samarium-153 EDTMP at onset of pain. J Bone Miner Metab. 2014;32:434-40.

11. Bander NH, Milowsky MI, Nanus DM, et al. Phase I trial of 177lutetium-labeled J591, a monoclonal antibody to prostate-specific membrane antigen, in patients with androgen-independent prostate cancer. J Clin Oncol. 2005;23:4591-601.

12. Tagawa ST, Milowsky MI, Morris M, et al. Phase II study of lutetium-177-labeled anti-prostatespecific membrane antigen monoclonal antibody J591 for metastatic castration-resistant prostate cancer. Clin Cancer Res. 2013;19:5182-91.

13. Kratochwil C, Giesel FL, Eder M, et al. 177Lu]Lutetiumlabelled PSMA ligand-induced remission in a patient with metastatic prostate cancer. Eur J Nucl Med Mol Imaging. 2015;42(6):987-8.

14. Hillier SM, Maresca KP, Femia FJ, et al. Preclinical evaluation of novel glutamate-urea-lysine analogues that target prostate-specific membrane antigen as molecular imaging pharmaceuticals for prostate cancer. Cancer Res. 2009;69(17):6932-40.

15. Weineisen M, Schottelius M, Simecek J, et al. 68Gaand 177Lu-Labeled PSMA I\&T: Optimization of a PSMAtargeted theranostic concept and first proof-of-concept human studies. J Nucl Med. 2015;56(8):1169-76.

16. Okamoto S, Thieme A, Allmann J, et al. Radiation dosimetry for ${ }^{177} \mathrm{Lu}$-PSMA I\&T in metastatic castration-resistant prostate cancer: absorbed dose in normal organs and tumor lesions. J Nucl Med. 2017;58(3):445-50.

17. Ahmadzadehfar H, Eppard E, Kürpig S, et al. Therapeutic response and side effects of repeated radioligand therapy with 177Lu-PSMA-DKFZ-617 of castrate-resistant metastatic prostate cancer. Oncotarget. 2016;7:12477-88.

18. Baum RP, Kulkarni HR, Schuchardt C, et al. Lutetium177 PSMA radioligand therapy of metastatic castration resistant prostate cancer: safety and efficacy. J Nucl Med. 2016;57:1006-13.

19. Ahmadzadehfar H, Rahbar K, Kürpig S, et al. Early side effects and first results of radioligand therapy with (177)Lu-
DKFZ-617 PSMA of castrate-resistant metastatic prostate cancer: a two-centre study. EJNMMI Res. 2015;5:114.

20. Heck MM, Retz M, Alessandria DC, et al. Systemic radioligand therapy with 177Lu-PSMA-I\&T in patients with metastatic castration-resistant prostate cancer. J Urol. 2016;196:382-91.

21. Kratochwil C, Giesel FL, Stefanova M, et al. PSMA-targeted radionuclide therapy of metastatic castration resistant prostate cancer with Lu-177 labeled PSMA-617. J Nucl Med. 2016;57(8):1170-6.

22. Rahbar K, Bode A, Weckesser M, et al. Radioligand Therapy With ${ }^{177} \mathrm{Lu}$-PSMA-617 as a novel therapeutic option in patients with metastatic castration resistant prostate cancer. Clin Nucl Med. 2016;41:522-8.

23. Rahbar K, Ahmadzadehfar H, Kratochwil C, et al. German multicenter study investigating 177Lu-PSMA-617 Radioligand therapy in advanced prostate cancer patients. J Nucl Med. 2017;58:85-90.

24. Kulkarni HR, Singh A, Schuchardt C, etal. PSMA-based radioligand therapy for metastatic castration-resistant prostate cancer: the Bad Berka experience since 2013. J Nucl Med. 2016;57(Suppl3):97S-104S.

25. Hofman MS, Violet J, Hicks RJ, Ferdinandus J, Thang SP, Akhurst T, et al. 177Lu]-PSMA-617 radionuclide treatment in patients with metastatic castration-resistant prostate cancer (LuPSMA trial): a single-centre, single-arm, phase 2 study. Lancet Oncol. 2018;19(6):825-33.

26. Rathke H, Giesel FL, Flechsig P, et al. Repeated 177LuLabeled PSMA-617 radioligand therapy using treatment activities of up to 9.3 GBq. J Nucl Med. 2018;59(3):459-65.

27. Kim YJ, Kim YI. Therapeutic responses and survival effects of 177Lu-PSMA-617 radioligand therapy in metastatic castrate-resistant prostate cancer: a meta-analysis. Clin Nucl Med. 2018;43:728-34.

28. Calopedos RJ, Chalasani V, Asher R, Emmett L, Woo HH. Lutetium-177-labelled anti-prostate-specific membrane antigen antibody and ligands for the treatment of metastatic castrate-resistant prostate cancer: a systematic review and meta-analysis. Prostate Cancer Prostatic Dis. 2017;20:352-60.

29. von Eyben FE, Roviello G, Kiljunen T, et al. Third-line treatment and 177Lu-PSMA radioligand therapy of metastatic castration-resistant prostate cancer: a systematic review. Eur J Nucl Med Mol Imaging. 2018;45:496-508.

30. Yadav MP, Ballal S, Sahoo RK, Dwivedi SN, Bal C. Radioligand therapy with 177Lu-PSMA for metastatic castrationresistant prostate cancer: a systematic review and metaanalysis. AJR Am J Roentgenol. 2019;213(2):275-85.

31. van Kalmthout L, Braat A, Lam M, etal. First experience with 177Lu-PSMA-617 therapy for advanced prostate cancer in the Netherlands. Clin Nucl Med. 2019;44(6):446-51.

Ludwike W.M. van Kalmthout, PhD-student, Resident Radiation Oncology

drs. Esmée C.A. van der Sar, physician researcher nuclear medicine

Arthur J.A.T. Braat, nuclear medicine physician

Bart de Keizer, nuclear medicine physician

Marnix G.E.H. Lam, nuclear medicine physician 